\title{
Antioxidant Potential of Red Palm-Pressed Mesocarp Olein
}

\author{
Soek Sin Teh ${ }^{1 *}$, Siau Hui Mah², Harrison Lik Nang Lau ${ }^{1}$, Kim Tiu Teng ${ }^{3}$, and \\ Radhika Loganathan ${ }^{3}$ \\ ${ }^{1}$ Energy and Environment Unit, Engineering and Processing Division, Malaysian Palm Oil Board, 6, Persiaran Institusi, Bandar Baru Bangi, \\ 43000 Kajang, Selangor, MALAYSIA \\ ${ }^{2}$ School of Biosciences, Taylor's University, Lakeside Campus, 47500 Subang Jaya, Selangor, MALAYSIA \\ ${ }^{3}$ Nutrition Unit, Product Development and Advisory Services Division, Malaysian Palm Oil Board, 43000 Kajang, Selangor, MALAYSIA
}

\begin{abstract}
Oxidative stress occurs due to the imbalance amount of the free radicals and antioxidants in human body which often associated with numerous chronic diseases. The antioxidant properties of red palm-pressed mesocarp olein (PPMO) have not been widely studied. Therefore, antioxidant properties of PPMO relative to commercially available edible oils, namely red palm olein (RPO), palm olein (PO), extra virgin olive oil (OO) and extra virgin coconut oil (CNO) were studied. PPMO exhibited significant higher phytonutrients which more than 2-fold compared to the edible oils. Overall, antioxidant screening indicated that PPMO has significantly higher antioxidant activities than RPO, PO and CNO in term of DPPH, $\mathrm{H}_{2} \mathrm{O}_{2}$, NO scavenging and FIC; and significantly higher $\mathrm{H}_{2} \mathrm{O}_{2}$ and FIC than OO. The outcomes of this study reveal that PPMO is as good as commercially available edible oil, also a good source for food applications and dietary nutritional supplements. More importantly, the utilization of PPMO could mitigate oil palm waste problem and results in positive environmental impact.
\end{abstract}

Key words: DPPH radical, hydrogen peroxide radical, nitric oxide radical, ferrous ion chelation

\section{Introduction}

Free radicals are highly reactive molecules, which are contributing to both beneficial and detrimental effects in the human body. They play important physiological roles such as cellular signalling, host defence mechanism, cell structures synthesis and blood pressure maintenance ${ }^{1,2}$. However, excessive free radicals in the body will lead to oxidative stress where the essential macromolecules such as proteins, lipids, carbohydrates and nucleic acids are damaged and resulting in cell death ${ }^{3)}$. Oxidative stress also promotes the process of aging, as well as decelerate cellular repairing process and collagen production. The phenomenon is often associated with various chronic diseases include inflammatory ${ }^{4)}$, atherosclerosis ${ }^{5)}$, cancer $^{6)}$, auto-immune disorder ${ }^{7)}$, asthma ${ }^{8)}$, diabetes ${ }^{5)}$ and neuro-degenerative $^{9)}$. Antioxidants are capable to neutralize free radicals effectively through their scavenging property, subsequently inhibit its destructive effect to the human body. Antioxidants could act as radical scavenger, hydrogen donor, electron donor, peroxide decomposer, singlet oxygen quencher, enzyme inhibitor, synergist or metal-chelating agents to inhibit cellular dysfunction ${ }^{10)}$.

Literature data showed that although micronutrients such as vitamin $\mathrm{C}$, vitamin $\mathrm{E}$ and beta-carotene are strong antioxidants, there is a concern on taking high doses of antioxidant supplements might do more harm than good. Scientific evaluation of natural products is challenging because of their immense complexity and variability. Natural products chemistry efforts are typically devoted to reducing complexity and identifying single active constituents for drug development. Many diseases are not regulated by a single molecular target, but often have a multi-factorial causality. Botanical extracts may contain hundreds or even more than thousands of individual metabolites at varying concentrations and identifying the compounds responsible for a given biological effect represents a significant challenge ${ }^{11)}$. The misconceptions of the behaviour of a mixture can be described by the presence of just a few known constituents are common. However, a number of studies have shown that the overall activity of botanical extracts can result from mixtures of phytochemicals with synergistic, additive, or antagonistic interactions, natural

\footnotetext{
* Correspondence to: Soek Sin Teh, Ph.D., Energy and Environment Unit, Engineering and Processing Division, Malaysian Palm Oil Board, 43000 Kajang, Selangor, MALAYSIA

E-mail: ssteh@mpob.gov.my

Accepted August 23, 2021 (received for review April 27, 2021)

Journal of Oleo Science ISSN 1345-8957 print / ISSN 1347-3352 online

http://www.jstage.jst.go.jp/browse/jos/ http://mc.manusriptcentral.com/jjocs

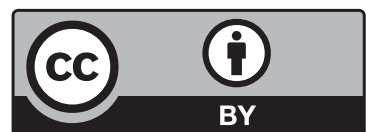


product chemists showed that it is very often where the isolation efforts on a botanical extract fail because activity is lost upon fractionation ${ }^{12,13)}$. Young et al. 1994 reported that the use of vitamin C may cause hazardous in the human body if excessive iron exist due to the formation of ascorbate that could exert prooxidant effects ${ }^{14)}$. Moreover, Bhat et al. 2006 reported that vitamin $\mathrm{C}$ at a concentration of 100-200 $\mu \mathrm{M}$ may cause oxidative DNA breakage in normal cells through Comet assay using human peripheral lymphocytes ${ }^{15)}$. A case report published in 2011 also showed that high intake of vitamin $\mathrm{C}$ will lead to oxalate nephropathy, revealing the potential renal injury resulted from an excessive intake amount ${ }^{16)}$. On the other hand, a meta-analysis carried out by Miller et al. 2005 showed a statistically significant relationship between vitamin E supplementation dosage and all-cause mortality, with an increased risk of dosages greater than $150 \mathrm{IU} / \mathrm{d}$ in a dose response analysis ${ }^{17)}$. In addition, a study involving a total of 59,910 French women demonstrated that $\beta$-carotene supplementation intake is significantly associated with the risk of tobacco-related cancers among smokers ${ }^{18)}$. There are a bunch of good evidences that consuming foods rich with antioxidants can help to boost immune system, protect against free radicals and may lower the risk of heart disease and cancer but it remains ambiguous and complicated when it comes to the intake of antioxidant supplements. Therefore, it urges researchers to find an alternative way to resolve the excessive production of free radicals in a safe manner which is from the foods that are rich in phytonutrients.

Palm-pressed mesocarp fiber is a cellulosic fibrous material obtained after screw-pressing of palm fruitlets in the palm oil mills. It contains typically $5 \%$ to $6 \%$ of residual oil (dry basis), which is known as palm-pressed mesocarp oil $^{19)}$. The oil can be recovered using supercritical carbon dioxide $\left(\mathrm{SC}-\mathrm{CO}_{2}\right)^{20)}$ and solvent extraction methods ${ }^{21}$. The high recovery rate of more than $90 \%{ }^{20}$ by using this extraction technology has generated extra revenue for the palm oil mills. Previous research studies indicated that the crude palm-pressed mesocarp oil is a rich source of naturally occurring phytonutrients such as carotenoids, vitamin E including tocopherol and tocotrienols, sterols, squalene ${ }^{19)}$, phospholipids ${ }^{22)}$ and water-soluble phenolic components ${ }^{23)}$. Thus, the nutritional value of mesocarp oil should be unveiled by transforming it into high value products and this is the first report on the antioxidant effects of red palmpressed mesocarp olein (PPMO).

The crude mesocarp oil could be further refined by removing the impurities including gum, waxes, trace metals and free fatty acids. The refined mesocarp oil subsequently fractionated into PPMO and stearin for niche product applications. The refining process to produce PPMO was reported previously by Lau et al. $2014^{24)}$. Both crude and refined red palm-pressed mesocarp oil have greater amount of phytonutrients if compared to other vegetable oils such as palm olein (PO), red palm olein (RPO), extra virgin olive oil $(\mathrm{OO})$ and extra virgin coconut oil $(\mathrm{CNO})^{25-33)}$. Generally, phytonutrients are desirable in food consumption for health benefits. Phytosterols have been proven scientifically to reduce low-density lipoprotein (LDL) and total cholesterol(TC) levels ${ }^{34}$, induce apoptosis in prostate ${ }^{35)}$, breast $^{36)}$ and colon ${ }^{37)}$ cancer cells, interrupt testosterone metabolism ${ }^{38)}$, and inhibit inflammation ${ }^{39)}$. Likewise, carotenoids possess anti-inflammatory, antioxidant and anticancer activities ${ }^{40)}$, as well as decreasing the risk of age-related macular degeneration and cataracts ${ }^{41}$. Besides the anti-oxidant and anticancer properties, squalene is able to lower the serum cholesterol levels ${ }^{42}$. Furthermore, vitamin E (tocols), had been proven to exert beneficial roles on neurological function ${ }^{43)}$ and anticlotting ${ }^{44)}$ activities.

$\mathrm{PO}$ is known to exert precious nutritional values due to its high content of phytosterols, tocotrienols and tocophenols, which exhibited antioxidant, anticancer and anti-inflammatory properties ${ }^{40,45,46)}$. RPO is rich in carotenoids and vitamin $\mathrm{E}$ and its preclinical studies demonstrated health beneficial effects in terms of reduction in LDL level and TC to high-density lipoprotein ratio (TC:HDL) ${ }^{47)}$, as well as lowered atherogenic effect ${ }^{48}$ if compared to that of PO. In addition, RPO supplementation exhibited heart protection against the consequences of ischemia/reperfusion injury ${ }^{49)}$. In contrast, the biological activities of the PPMO have yet to be assessed and compared with other vegetable oils. OO and CNO have been well studied for their biological activities and therefore these oils were selected for comparison purpose in this study. The evergreen olive cultivar (Olea europea L., Oleaceae) is a valuable Mediterranean tree, which provides a unique flavour with nutritional benefits. It contains a number of bioactive components that showed antioxidant and anti-inflammatory properties such as polyphenols, phytosterols and vitamin $\mathrm{E}^{50,51)}$. On the other hand, preclinical studies revealed that the CNO supplemented diet exhibited antioxidant activity by increasing antioxidant enzymes and reducing lipid peroxidation content ${ }^{52}$. CNO supplementation also exhibited antioxidant and hepatoprotective effects against oxidative stress and liver damage induced by anticancer drug methotrexate in rats. Thus, this study was conducted to assess antioxidant properties of PPMO, PO, RPO, OO and CNO.

\section{Materials and Methods \\ 2.1 Materials}

PPMO was obtained according to the method described by Sulihatimarsyila et al. $2019^{21)}$. In brief, crude palmpressed mesocarp oil was obtained from a local palm oil mill in Malaysia. The oil was degummed, deacidified, deodorized and fractionated to obtain the refined red palm- 
pressed mesocarp oil. The refining condition was using hot distilled water and phosphoric acid for degumming and natural bleaching earth for bleaching, as well as deodorization at temperature lower than $200^{\circ} \mathrm{C}$. The refined red palm-pressed mesocarp oil was then fractionated to obtain two fractions which were red palm-pressed mesocarp stearin (solid fraction) and PPMO (liquid fraction). PO, $\mathrm{RPO}, \mathrm{OO}$ and $\mathrm{CNO}$ were purchased from local supermarket in Malaysia. All the chemicals, reagents and media were purchased from Sigma Aldrich (Switzerland), Merck Sdn. Bhd. (Germany), R\&M Sdn. Bhd. (Malaysia) and Team Medical \& Scientific Sdn. Bhd. (Malaysia).

\subsection{Methods}

\subsubsection{Chemical constituents of PPMO}

\subsubsection{Sterol Composition and Squalene Content}

The sterol composition and squalene content were determined simultaneously ${ }^{53)}$. The gas chromatograph (GC, 7890B Agilent, Agilent Technologies, USA) on a CP9078 select biodiesel for glycerides, UM + 2m RG column of $15 \mathrm{~m}$ (L) $\times 320 \mu \mathrm{m}(\mathrm{D}) \times 0.1 \mu \mathrm{m}($ Film $)$ coupled with a FID was used. The flow rate of carrier gas, helium was $5 \mathrm{~mL} / \mathrm{min}$. The injector, detector and oven temperatures were set at $50^{\circ} \mathrm{C}, 380^{\circ} \mathrm{C}$ and $370^{\circ} \mathrm{C}$, respectively. Identification of sterol composition and squalene content in the oils was done by comparing their retention times with commercial standards, Mono C19, Di C38, Tri C57, squalene and cholesterol.

\subsubsection{Total Catotene Content}

Total carotene content of the oils was conducted using MPOB Test Method p2.6:2004 $4^{54)}$. Approximately $0.1 \mathrm{~g}$ of oil was dissolved in $250 \mathrm{~mL}$ of $n$-hexane. The absorbance of oil extract was measured at $446 \mathrm{~nm}$. The total carotene content of the oils was expressed in $\mathrm{mg} / \mathrm{kg}$, was defined and calculated as $\beta$-carotene.

\subsubsection{Vitamin E Composition}

The tocopherols and tocotrienols of the oils were analysed using a HPLC (Agilent 1100 series, Agilent Technologies, USA), equipped with a normal phase Supelco Ascentis ${ }^{\circledR}$ Si column $(150 \mathrm{~mm} \times 4.6 \mathrm{~mm} \times 5 \mu \mathrm{m}$ particle size $)$ coupled to a fluorescence detector according to Che et $a l .{ }^{55)}$ with some modifications. The detection wavelengths for excitation and emission were 270 and $315 \mathrm{~nm}$, respectively. The mobile phase used was a mixed $n$-heptane and ethyl acetate at $97: 3 \%(\mathrm{v} / \mathrm{v})$.

\subsubsection{Preparation of Oil Extracts}

The polar compounds from oil samples were extracted according to the methods as described by Radhia et al. $2017^{56)}$ with minor modifications. Approximately $1 \mathrm{~g}$ of oil sample was mixed with $1 \mathrm{~mL}$ of extraction solvent, which was methanol:water $(80: 20 \mathrm{v} / \mathrm{v})$. The oil-solvent mixture was vortexed for $10 \mathrm{~min}$ and left to stand for approximately $1 \mathrm{~h}$ until the two layers were formed. The upper layer was collected through careful pipetting. The extraction process was repeated twice. The oil extracts were combined and stored in a scintillation vial at $4^{\circ} \mathrm{C}$ for subsequent bioassays. The concentration of the oil extracts was noted as $330 \mu \mathrm{g} / \mathrm{mL}$.

2.2.2.1 Total Phenolic Content (TPC)

TPC analysis of the oil extracts was carried out using Folin-Ciocalteau (FC) method as described by Abdullah et al. $2018^{57}$. Gallic acid (GA) was used to plot the standard curve that was constructed by a range of concentrations $(20,40,60,80$ and $100 \mu \mathrm{g} / \mathrm{mL})$ dissolved with the extraction solvent. The equation of $y=0.7996 x+0.1162$ with a $R^{2}$ value of 0.9949 was obtained, where $y$ is the absorbance at $765 \mathrm{~nm}$ and $x$ is the GA concentration with a unit of $\mu \mathrm{g} / \mathrm{mL}$. TPC of the oil extracts was expressed as GA equivalent per gram of oil extract ( $\mu \mathrm{g} \mathrm{GAE} / \mathrm{g}$ oil extract).

2.2.2.2 Total Flavonoid Content (TFC)

TFC of the oil extracts was determined using the aluminium chloride $\left(\mathrm{AlCl}_{3}\right)$ colorimetric method as described by Radhia et al. $2017^{56)}$ where rutin hydrate was used as the standard compound. A standard curve of rutin hydrate was constructed using a series of concentrations of 20,40 , 60,80 and $100 \mu \mathrm{g} / \mathrm{mL}$ by serial dilution using the extraction solvent. The equation of $y=0.5248 x-1.1534\left(R^{2}=0.9982\right)$ was obtained where $y$ is the absorbance at $420 \mathrm{~nm}$ and $x$ is the rutin concentration in $\mu \mathrm{g} / \mathrm{mL}$. TFC of the oil extracts was presented as rutin hydrate equivalent per gram of oil extract ( $\mu$ g RE/g oil extract).

2.2.3 Antioxidant Assays

2.2.3.1 $\alpha, \alpha$-diphenyl- $\beta$-picrylhydrazyl (DPPH) Radical Scavenging Assay

The DPPH radical scavenging assay of the oil extracts was conducted according to Teh et al. 2013 ${ }^{58)}$. Ascorbic acid (vitamin C) was used as a standard drug in this assay. The absorbance of each well was recorded at $517 \mathrm{~nm}$ using a microplate reader. The percentage of total radical scavenging activity was calculated by using the formula below:

Percentage of DPPH scavenging activity $(\%)=(\mathrm{A}-\mathrm{B}) /$ $\mathrm{A} \times 100$, where, $\mathrm{A}$ equals to absorbance of control and $\mathrm{B}$ equals to absorbance of oil extract

\subsubsection{Hydrogen Peroxide $\left(\mathrm{H}_{2} \mathrm{O}_{2}\right)$ scavenging assay}

The $\mathrm{H}_{2} \mathrm{O}_{2}$ scavenging assay was performed according to the method reported by Fernando and Soysa ${ }^{59)}$ with some modification. Ascorbic acid was used as a standard drug and the absorbance was determined immediately at 230 nm against a blank solution by using UV spectrophotometer (Lambda XLS, Perkin Elmer). The $\mathrm{H}_{2} \mathrm{O}_{2}$ scavenging activity was calculated using the formula below:

Percentage of $\mathrm{H}_{2} \mathrm{O}_{2}$ Scavenging Activity $(\%)=(\mathrm{A}-\mathrm{B}) / \mathrm{A}$ $\times 100$

where, A equals to absorbance of control and B equals to 
absorbance of oil extract

2.2.3.3 Nitric Oxide (NO) Radical Scavenging Assay

The NO radical scavenging activity of samples was determined by referring to the method described by Parul, Kundu and Saha ${ }^{60)}$ with minor modifications. Ascorbic acid was used as a standard and the absorbance was read at 546 nm using a microplate reader. The NO radical scavenging activity was calculated using the formula:

\section{Percentage of NO Scavenging $\operatorname{Activity}(\%)=(\mathrm{A}-\mathrm{B}) / \mathrm{A}$ $\times 100$}

where, A equals to absorbance of control and B equals to absorbance of oil extract

\subsubsection{Ferrous Ion Chelating (FIC) Assay}

The FIC activity of the oil extracts was determined according to the method described by Mah et al. $2017^{61)}$. Ethylenediaminetetraacetic acid (EDTA) was used as the standard compound and the absorbance of each well was then measured at $595 \mathrm{~nm}$.

The percentage inhibition of the ferrozine- $\mathrm{Fe}^{2+}$ complex formation was calculated as $\left[\left(\mathrm{A}_{0}-\mathrm{A}_{\mathrm{S}}\right) / \mathrm{A}_{\mathrm{S}}\right] \times 100$, where $\mathrm{A}_{0}$ is the absorbance of the control and $A_{S}$ is the absorbance of the sample.

\subsubsection{Ferric Reducing Antioxidant Power (FRAP)}

The FRAP of the oil extracts was determined according to the method reported by Mah et al. 2017 ${ }^{61)}$ where ascorbic acid (AA) was used as the standard compound. A standard curve was constructed by using AA with a series of concentrations $(200,400,600,800$ and $1000 \mu \mathrm{g} / \mathrm{mL})$ in the extraction solvent. The equation $y=0.0121 x+0.7417$ with $R^{2}$ value of 0.9967 was obtained where $y$ is the absorbance at $650 \mathrm{~nm}$ and $x$ is the concentration of AA in $\mu \mathrm{g} / \mathrm{mL}$. The results of FRAP are expressed as AA equivalent per gram of oil extract ( $\mu \mathrm{g}$ AAE/ g oil extract). The experiments were carried out in triplicates.

\subsubsection{Statistical Analysis}

All the data were presented in mean and statistical analyses were performed by using GraphPad Prism 7. Data were analysed by one-way ANOVA and two-way ANOVA, followed by Tukey's Multiple Comparison Test. In addition, Pearson correlation was performed to determine the relationship between phytonutrients in oils and the antioxidant activities where " 0 " indicates no association, " $0<$ correlation coefficient value $(r) \leq 0.2$ " indicates weakly association, " $0.2<r \leq 0.5$ " indicates moderately association, " $0.5<r \leq$ 0.8 " indicates strongly association, and lastly " $0.8<r \leq$ 1.0 " indicates perfectly association. The $p$ value $\leq 0.05$ was considered to be statistically significant.

\section{Results and Discussion}

PPMO was extracted with hexane where the breakdown of phospholipid bilayer in mesocarp was involved. Crude palm oil was extracted with mechanical pressing method, also known as screw pressing where the oil was extracted without disrupting the membrane layer, subsequently subjected to refining process including degumming, deacidification and fractionation to obtain RPO. Meanwhile, bleaching process was performed on RPO to obtain PO. Both OO and CNO were obtained through cold pressing method. Different extraction methods could lead to different levels of phytonutrients in the oils.

All the edible oils were extracted for their polar components and evaluated for their TPC, TFC and antioxidant activities. The TPC and TFC results of the oil extracts were summarized in Table 1. The TPC results showed that PPMO has comparable values with PO and RPO. However, the TPC value of RPO is significantly higher than PO, which might be due to the removal of polar carotenoids such as zeaxanthin, violaxanthin, and lutein during the bleaching process. Results showed that the TPC value of

Table 1 Total phenolic contents (TPC) and total flavonoid contents (TFC) of the oil extracts.

\begin{tabular}{cccc}
\hline Oil Extract & $\begin{array}{c}\text { TPC }(\mu \mathrm{g} \text { GAE/g oil } \\
\text { extract })\end{array}$ & $\begin{array}{c}\text { TFC }(\mu \mathrm{g} \text { RE/g oil } \\
\text { extract })\end{array}$ & $\begin{array}{c}\text { Significant difference } \\
\text { between TPC and } \\
\text { TFC }\end{array}$ \\
\hline PPMO & $3.81 \pm 0.37^{\mathrm{b}, \mathrm{c}}$ & $5.58 \pm 0.29^{\mathrm{b}}$ & $p>0.05$ \\
PO & $3.26 \pm 0.17^{\mathrm{a}, \mathrm{b}}$ & $4.76 \pm 0.64^{\mathrm{a}, \mathrm{b}}$ & $p>0.05$ \\
RPO & $5.72 \pm 0.10^{\mathrm{c}}$ & $4.80 \pm 0.80^{\mathrm{a}, \mathrm{b}}$ & $p>0.05$ \\
OO & $61.87 \pm 1.53^{\mathrm{d}}$ & $7.28 \pm 2.01^{\mathrm{b}}$ & $p<0.05$ \\
CNO & $1.74 \pm 0.12^{\mathrm{a}}$ & $2.49 \pm 0.19^{\mathrm{a}}$ & $p>0.05$ \\
\hline
\end{tabular}

Note: Each data represents the mean \pm SD of three independent experiments where means with different letters in the same column indicate significant differences $(p<0.05)$. PPMO: red palm-pressed mesocarp olein; PO: palm olein; RPO: red palm olein; OO: extra virgin olive oil; $\mathrm{CNO}$ : extra virgin coconut oil. 
PPMO is significantly lower than OO but relatively higher than $\mathrm{CNO}$, also the TPC value of OO is significantly higher than $\mathrm{CNO}$ even though both $\mathrm{OO}$ and $\mathrm{CNO}$ were processed using the same method, which is cold pressing method. The remarkably high TPC value of OO is in good agreement with the literature data where $\mathrm{OO}$ is rich in phenolics, which are constituted of both lipophilic and hydrophilic compounds $^{62}$. The hydrophilic phenolic compounds include phenolic acids, phenolic alcohols, flavonoids, lignans, secoiridoids and their derivatives ${ }^{62}$. The results postulate that the amount of TPC in oil extracts is highly correlated to the naturally occurring metabolites but not solely to the processing methods.

Flavonoid is one type of the phenolic compounds that are widely distributed in the plants. There was no significant difference observed for the TPC and TFC values of PPMO, PO, RPO and CNO. The results postulate that the phenolic compounds exist in the oil extracts are mostly presented as polyphenolic compounds, flavonoids. Meanwhile, the TPC value in $\mathrm{OO}$ was found to be significantly higher than its TFC value owing to most of the phenolic compounds present are different classes from flavonoid. The findings are in good agreement with the literature data where the main constituents are hydroxytyrosol (class of phenolic acid) and oleuropein (class of glycosylated secoiri(doid $)^{63)}$.

DPPH, $\mathrm{H}_{2} \mathrm{O}_{2}$ and NO radicals scavenging assay were conducted to assess the radical scavenging capacity of the edible oils. Ascorbic acid was selected as the standard drug for these antioxidant assay due to its well-known strong antioxidant activities ${ }^{64)}$. The overall results, which were presented in Table 4, demonstrated that the PPMO possess good antioxidant property in terms of radicals scavenging capability. OO recorded the highest DPPH scavenging activity, followed by PPMO, RPO, PO and CNO. The outcome can be explained by the phytonutrients in each oil where squalene and TPC are significantly associated with DPPH scavenging activity as shown in Tables 1,2 and 5. There is almost all the phytonutrients are strongly associated either positively or negatively with $\mathrm{H}_{2} \mathrm{O}_{2}$ scavenging effect, except for TFC which correlated moderately (Tables 1-5).

Therefore, even $\mathrm{OO}$ exhibited highest DPPH scavenging effect but it marked the lowest $\mathrm{H}_{2} \mathrm{O}_{2}$ scavenging activities as the high concentration of TPC and squalene are strongly negatively associated with the activity which in turn diminished $\mathrm{H}_{2} \mathrm{O}_{2}$ scavenging effect possessed by other phytonutrients. The finding showed that PPMO exhibited the strongest scavenging activity towards $\mathrm{H}_{2} \mathrm{O}_{2}$ radical among the oil extracts with $50.5 \%$ at the concentration of $50 \mu \mathrm{g} /$ $\mathrm{mL}$ (Tables 1-5). The diminishment effect by squalene and TPC towards the activity was not significantly affected PPMO as it has the remarkably high levels of carotene and vitamin $\mathrm{E}$, where both are perfectly associated with $\mathrm{H}_{2} \mathrm{O}_{2}$ scavenging effect $(r>0.8)$, which in turn counterbalance the diminishment effect. Literature data showed that carotenoids could scavenge $\mathrm{H}_{2} \mathrm{O}_{2}$ radicals effectively ${ }^{65)}$. A previous study also acknowledged the antioxidant capacity of the extracts of oil palm fruit through $\mathrm{H}_{2} \mathrm{O}_{2}$ scavenging $\operatorname{assay}^{66)}$.

For the NO radical scavenging activities, PPMO showed comparable effect with $\mathrm{OO}$ with $26.3 \%$ and $27.5 \%$, respectively as the TFC and squalene exhibited strongest association among all the phytonutrients where OO exhibited the highest, followed by PPMO. However, there is no significant different between NO scavenging effect of PPMO and OO which might owing to the high concentration of sterol and $\alpha$-tocopherol in PPMO (Tables 1-5). The findings are in line with literature data where $\alpha$-tocopherol and phytosterol have been reported as antioxidants by breaking freeradical chain reactions ${ }^{67)}$ and stabilizing liposomal membranes $^{68)}$, respectively.

Even though PPMO has a certain degree of radical scavenging properties, it is not as effective as the standard drug, ascorbic acid. Generally, the radicals scavenging activity of oil palm based edible oils, including PPMO, PO and $\mathrm{RPO}$ are stronger than CNO. The activities are postulated

Table 2 Total carotene, squalene and sterol contents of the oils.

\begin{tabular}{ccccc}
\hline & \multicolumn{4}{c}{ Concentration $(\mathrm{ppm})$} \\
\cline { 2 - 5 } & Carotene & Squalene & Sterol & Vitamin E \\
\hline PPMO & $1312 \pm 14^{\mathrm{b}}$ & $401 \pm 14^{\mathrm{b}}$ & $519 \pm 8^{\mathrm{d}}$ & $1643 \pm 13^{\mathrm{d}}$ \\
PO & ND & $106 \pm 11^{\mathrm{a}}$ & $160 \pm 5^{\mathrm{a}}$ & $761 \pm 3^{\mathrm{b}}$ \\
RPO & $571 \pm 35^{\mathrm{a}}$ & $83 \pm 10^{\mathrm{a}}$ & $185 \pm 7^{\mathrm{b}}$ & $894 \pm 9^{\mathrm{c}}$ \\
OO & ND & $1323 \pm 15^{\mathrm{c}}$ & $235 \pm 12^{\mathrm{c}}$ & $223 \pm 2^{\mathrm{a}}$ \\
CNO & ND & ND & ND & ND \\
\hline
\end{tabular}

Note: Each data represents the mean $\pm \mathrm{SD}$ of three independent experiments where means with different letters in the same column indicate significant differences $(p<0.05)$. PPMO: red palm-pressed mesocarp olein; PO: palm olein; OO: extra virgin olive oil; $\mathrm{CNO}$ : extra virgin coconut oil; ND: not detectable 
S. S. Teh, S. H. Mah, H. L. N. Lau et al.

Table 3 Vitamin E composition of the oils.

\begin{tabular}{cccccc}
\hline & PPMO & PO & RPO & OO & CNO \\
\hline$\alpha$-tocopherol & $857 \pm 12^{\mathrm{c}}$ & $159 \pm 2^{\mathrm{a}}$ & $156 \pm 2^{\mathrm{a}}$ & $210 \pm 2^{\mathrm{b}}$ & $\mathrm{ND}$ \\
$\alpha$-tocotrienol & $363 \pm 6^{\mathrm{c}}$ & $241 \pm 1^{\mathrm{a}}$ & $296 \pm 16^{\mathrm{b}}$ & $\mathrm{ND}$ & $\mathrm{ND}$ \\
$\beta$-tocopherol & $\mathrm{ND}$ & $\mathrm{ND}$ & $\mathrm{ND}$ & $\mathrm{ND}$ & $\mathrm{ND}$ \\
$\beta$-tocotrienol & $34 \pm 1^{\mathrm{a}}$ & $25 \pm 3^{\mathrm{a}}$ & $31 \pm 3^{\mathrm{a}}$ & $\mathrm{ND}$ & $\mathrm{ND}$ \\
$\gamma$-tocopherol & $\mathrm{ND}$ & $\mathrm{ND}$ & $\mathrm{ND}$ & $13 \pm 1$ & $\mathrm{ND}$ \\
$\gamma$-tocotrienol & $343 \pm 5^{\mathrm{a}}$ & $293 \pm 2^{\mathrm{a}}$ & $327 \pm 8^{\mathrm{a}}$ & $\mathrm{ND}$ & $\mathrm{ND}$ \\
$\delta$-tocopherol & $\mathrm{ND}$ & $\mathrm{ND}$ & $\mathrm{ND}$ & $\mathrm{ND}$ & $\mathrm{ND}$ \\
$\delta$-tocotrienol & $46 \pm 1^{\mathrm{a}}$ & $43 \pm 1^{\mathrm{a}}$ & $84 \pm 4^{\mathrm{b}}$ & $\mathrm{ND}$ & $\mathrm{ND}$ \\
\hline $\begin{array}{c}\text { Total tocopherol, } \\
\mathrm{T}(\mathrm{ppm})\end{array}$ & $857 \pm 12^{\mathrm{c}}$ & $159 \pm 2^{\mathrm{a}}$ & $156 \pm 2^{\mathrm{a}}$ & $223 \pm 3^{\mathrm{b}}$ & $\mathrm{ND}$ \\
\hline Total tocotrienol, \\
T3 $(\mathrm{ppm})$
\end{tabular}

Note: Each data represents the mean \pm SD of three independent experiments where means with different letters in the same row indicate significant differences $(p<0.05)$. PPMO: red palmpressed mesocarp olein; PO: palm olein; OO: extra virgin olive oil; CNO: extra virgin coconut oil; ND: not detectable

Table 4 Antioxidant properties of oil extracts.

\begin{tabular}{ccccc}
\hline \multirow{2}{*}{ Oil Extract } & $\begin{array}{c}\text { DPPH } \\
\text { Scavenging (\%) }\end{array}$ & $\begin{array}{c}\mathrm{H}_{2} \mathrm{O}_{2} \\
\text { Scavenging }(\%)\end{array}$ & $\begin{array}{c}\text { NO } \\
\text { Scavenging (\%) }\end{array}$ & $\begin{array}{c}\text { Ferrous Ion } \\
\text { Chelation (\%) }\end{array}$ \\
\hline PPMO & $30.5 \pm 1.7^{\mathrm{c}}$ & $50.5 \pm 0.2^{\mathrm{d}}$ & $26.3 \pm 0.8^{\mathrm{c}, \mathrm{d}}$ & $29.5 \pm 3.2^{\mathrm{b}}$ \\
PO & $9.5 \pm 0.4^{\mathrm{a}}$ & $34.0 \pm 0.0^{\mathrm{c}}$ & $24.4 \pm 1.1^{\mathrm{b}, \mathrm{c}}$ & $5.9 \pm 0.9^{\mathrm{a}}$ \\
RPO & $20.9 \pm 1.7^{\mathrm{b}}$ & $34.0 \pm 0.1^{\mathrm{c}}$ & $22.5 \pm 1.0^{\mathrm{a}, \mathrm{b}}$ & $26.2 \pm 0.7^{\mathrm{b}}$ \\
OO & $76.6 \pm 1.1^{\mathrm{d}}$ & $18.0 \pm 0.1^{\mathrm{a}}$ & $27.5 \pm 0.7^{\mathrm{d}}$ & $7.5 \pm 2.8^{\mathrm{a}}$ \\
CNO & $6.9 \pm 0.9^{\mathrm{a}}$ & $31.5 \pm 0.0^{\mathrm{b}}$ & $21.9 \pm 0.8^{\mathrm{a}}$ & $7.3 \pm 0.6^{\mathrm{a}}$ \\
AA & $100.0 \pm 0.0$ & $92.59 \pm 1.27$ & $51.91 \pm 1.51$ & - \\
EDTA & - & - & - & $100 \pm 0.00$ \\
\hline
\end{tabular}

Note: Each data represents the mean \pm SD of three independent experiments where means with different letters in the same column indicate significant differences $(p<0.05)$. PPMO: red palmpressed mesocarp olein; PO: palm olein; OO: extra virgin olive oil; CNO: extra virgin coconut oil; AA: ascorbic acid; EDTA: Ethylenediaminetetraacetic acid. '- ' means not tested. ND: not detectable. The concentration of the oil extract used: $\mathrm{DPPH}=333 \mu \mathrm{g} / \mathrm{mL} ; \mathrm{H}_{2} \mathrm{O}_{2}=50 \mu \mathrm{g} / \mathrm{mL} ; \mathrm{NO}$ $=5 \mu \mathrm{g} / \mathrm{mL}$; Ferrous ion chelation $=333 \mu \mathrm{g} / \mathrm{mL}$.

to be attributed to the presence of TPC, carotene, sterol, squalene and vitamin $\mathrm{E}$ that are known for their potent antioxidant activity ${ }^{69)}$. Moreover, this finding further confirms that the oil palm-based edible oil, is rich of antioxidants that act on radicals.

Alternatively, antioxidant can act on the chelation of iron by binding directly with iron so that the iron-chelator complex will then be excreted from human body in the forms of urine or faeces. Iron plays an essential role in promoting the formation of blood but excessive iron in the body will result in iron-mediated oxidative stress ${ }^{14)}$. Free iron is a potent promoter of hydroxyl radical formation that can cause increased lipid peroxidation and depletion of antioxidants, eventually leading to increased susceptibility to infection, veno-occlusive disease and chronic liver diseas$\mathrm{es}^{70}$. FIC assay was performed to determine the chelation ability of the oil extracts. EDTA, which was used a standard drug in this assay, exhibited strong chelating activity as supported by previous study ${ }^{71)}$. PPMO and RPO oil extracts exhibited comparable FIC activity and their activities were significantly stronger than $\mathrm{OO}, \mathrm{CNO}$ and $\mathrm{PO}$. The significantly lower chelating of PO than RPO might due to the removal of carotene compounds from RPO during bleaching process and the lower vitamin $\mathrm{E}$ content than RPO 
Table 5 Pearson correlation analysis between phytonutrients and antioxidant activities of the oils.

\begin{tabular}{cccccc}
\hline \multirow{2}{*}{ Phytonutrients } & \multicolumn{5}{c}{ Correlation Coefficient Value $(r)$} \\
\cline { 2 - 6 } & $\begin{array}{c}\mathrm{DPPH} \\
\text { Scavenging }\end{array}$ & $\begin{array}{c}\mathrm{H}_{2} \mathrm{O}_{2} \\
\text { Scavenging }\end{array}$ & $\begin{array}{c}\mathrm{NO} \\
\text { Scavenging }\end{array}$ & $\begin{array}{c}\text { Ferrous Ion } \\
\text { Chelation }\end{array}$ & $\begin{array}{c}\text { Ferric Ion Reducing } \\
\text { Antioxidant Power }\end{array}$ \\
\hline $\mathrm{TPC}$ & $0.95^{*}$ & -0.75 & 0.70 & -0.34 & $0.98^{*}$ \\
$\mathrm{TFC}$ & 0.88 & -0.26 & $0.89^{*}$ & 0.13 & 0.84 \\
Carotene & -0.04 & 0.84 & 0.21 & $0.93^{*}$ & -0.26 \\
Squalene & $0.99^{*}$ & -0.54 & 0.85 & -0.18 & $0.94^{*}$ \\
Sterol & 0.35 & 0.60 & 0.68 & 0.70 & 0.13 \\
Vitamin E & -0.12 & 0.84 & 0.28 & 0.82 & -0.28 \\
\hline$\alpha$-tocopherol & 0.19 & 0.73 & 0.57 & 0.70 & -0.07 \\
$\alpha$-tocotrienol & -0.33 & 0.81 & 0.01 & 0.78 & -0.41 \\
$\beta$-tocotrienol & -0.36 & 0.77 & -0.03 & 0.76 & -0.41 \\
$\gamma$-tocotrienol & -0.39 & 0.74 & -0.05 & 0.70 & -0.42 \\
$\delta$-tocotrienol & -0.36 & 0.50 & -0.27 & 0.71 & -0.31 \\
Total T & 0.20 & 0.72 & 0.58 & 0.69 & -0.05 \\
Total T3 & -0.37 & 0.76 & -0.04 & 0.75 & -0.41 \\
\hline
\end{tabular}

Note: * indicates significant differences $(p<0.05)$. T: tocopherol; T3: tocotrienol.

(Tables 3 and 5). Previous studies on iron uptake by human colorectal adenocarcinoma cells, Caco-2 showed that carotenoids significantly increased iron uptake from ferrous fumarate and NaFe-EDTA, and were capable of partially overcoming the inhibition produced by tannic $\operatorname{acid}^{72)}$. Thus, the weaker activities shown by the oil extracts in the FIC assay is possibly due to lack of the carotenoids that are efficient in ferrous ion binding activity.

The total antioxidant capacity of the oil extracts was examined by FRAP method, which relies on the reduction of the complex ferric ion-TPTZ (2,4,6-tri (2-pyridyl)-1,3,5-triazine) by antioxidants. An intense blue color solution will be formed when ferric tripyridyl triazine $\left(\mathrm{Fe}^{3+} \mathrm{TPTZ}\right)$ complex is reduced to the ferrous $\left(\mathrm{Fe}^{2+}\right)$ form, where the absorbance can be measured to quantify the amount of ferric ion being reduced and correlate it to the amount of antioxidants present. The results were presented in Fig. 1. OO has the strongest reducing power among the oil extracts with the value of $1411 \mu \mathrm{g}$ AAE/g oil extract. This value is significantly higher than the other oil extracts, which are in the FRAP value order of $\mathrm{RPO}>\mathrm{PO}>\mathrm{PPMO}>$ CNO. The findings follow the same trend of the difference between TPC and TFC (Table 1). Literature data showed that FRAP method has limitation which is unable to measure polyphenolic compounds and thiols in which the total reducing power was significantly correlated with the phenolic compounds ${ }^{73}$ and squalene (Table 5). The results are in good agreement with the literature data where most of the compounds in $\mathrm{OO}$ are not phenolic compounds as a huge difference was observed between the TPC and TFC

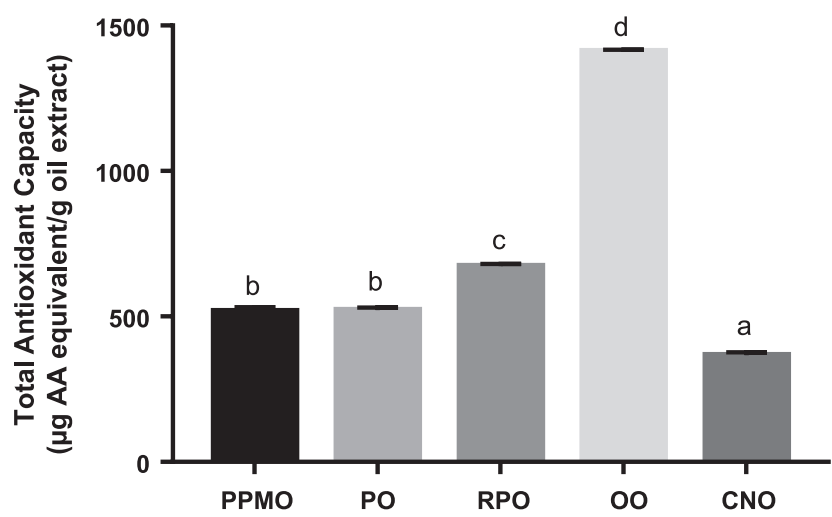

Fig. 1 Ferric ion reducing antioxidant power (FRAP) of oil extracts.

Note: Each data represents the mean \pm SD of three independent experiments where means with different letters indicate significant differences $(p<0.05)$. Each data represents the mean $\pm \mathrm{SD}$ of three independent experiments. PPMO: red palm-pressed mesocarp olein; PO: palm olein; RPO: red palm olein; OO: extra virgin olive oil; CNO: extra virgin coconut oil. AA: ascorbic acid.

values, therefore, a great discrepancy was observed between $\mathrm{OO}$ and the other oil extracts.

In summary, PPMO possesses the strongest $\mathrm{H}_{2} \mathrm{O}_{2}$ scavenging and FIC activities among the oil extracts. Thus, PPMO is a good source of antioxidants that are worth to be considered as a nutritious food due to its phytonutrients including carotenoids, vitamin $\mathrm{E}$ and phytosterols. 


\section{Conclusion}

In conclusion, PPMO exhibited significant higher phytonutrients which more than 2-fold compared to the edible oils. The results indicated that PPMO has comparable TPC and TFC levels when compared with PO, RPO and CNO but significantly lower levels than in the $\mathrm{OO}(p<0.05)$. The DPPH scavenging activity of oil extracts was in the order of $\mathrm{OO}>\mathrm{PPMO}>\mathrm{RPO}>\mathrm{PO}>\mathrm{CNO}$ whereas different order was recorded by FRAP method which was $\mathrm{OO}>\mathrm{RPO}>$ $\mathrm{PPMO}>\mathrm{PO}>\mathrm{CNO}$. In addition, PPMO oil extract exhibited comparable FIC activity with RPO and had significantly higher FIC activity than $\mathrm{OO}, \mathrm{CNO}$ and $\mathrm{PO}(p<0.05)$. The correlation analysis showed that different photometric measurement plays an important role in determining antioxidant activity as synergistic and antagonistic effects between the components in the oil extracts existed. Overall, antioxidant screening indicated that PPMO has significantly higher antioxidant activities (DPPH, FIC and FRAP) than PO and CNO; and significantly higher FIC activity than OO. The outcomes of this study reveal that PPMO is as good as commercially available cooking oil and could be a good source of phytonutrient to be applied in food industry. More importantly, value discovery of PPMO could encourage the recovery and refining of residual pressed-mesocarp fibre oil in the palm oil mills and increase revenue of the oil palm industry.

\section{Conflict of Interest}

None of the authors had a conflict of interest.

\section{Author Contributions}

All authors were responsible for the design and execution of the study. Teh S.S. performed the hands-on experiments, namely: conceptualization, methodology, validation, formal analysis, investigation, writing- original draft preparation. Mah S. H. performed the hands-on experiments, namely: conceptualization, methodology, validation, formal analysis and investigation. Lau H.L.N., Teng K.T. and Loganathan $R$. reviewed, read and approved the final version.

\section{Acknowledgments}

We would like to thank the Director General of MPOB for permission to publish these data. The authors would like to acknowledge financial support from Malaysian Palm Oil Board (MPOB) and Malaysian Ministry of Education (MOE) under the Fundamental Research Grant Scheme (FRGS/1/2019/STG01/TAYLOR/02/1).

\section{References}

1) Pizzino, G.; Irrera, N.; Cucinotta, M.; Pallio, G.; Mannino, F.; Arcoraci, V.; Squadrito, F.; Altavilla, D.; Bitto, A. Oxidative stress: harms and benefits for human health. Oxid. Med. Cell. Longev. 2017, 8416763(2017).

2) Nahar, M.; Hasan, W.; Rajak, R.; Jat, D. Oxidative stress and antioxidants: An overview. Int. J. Adv. Res. Rev. 2(9), 110-119(2017).

3) Irshad, M.; Chaudhuri, P.S. Oxidant-antioxidant system: Role and significance in human body. Indian Journal of Experimental Biology 40, 1233-1239 (2002).

4) Conner, E.M.; Grisham, M.B. Inflammation, free radicals, and antioxidants. Nutrition 12, 274-277 (1996).

5) Singh, R.; Devi, S.; Gollen, R. Role of free radical in atherosclerosis, diabetes and dyslipidaemia: Largerthan-life. Diabetes Metab. Res. Rev. 31, 113-126 (2015).

6) Dreher, D.; Junod, A.F. Role of oxygen free radicals in cancer development. Eur. J. Cancer 32a, 30-38 (1996).

7) Srivastava, S.; Singh, D.; Patel, S.; Singh, M.R. Role of enzymatic free radical scavengers in management of oxidative stress in autoimmune disorders. Int. J. Biol. Macromol. 101, 502-517(2017).

8) Cho, Y. S.; Moon, H.-B. The role of oxidative stress in the pathogenesis of asthma. Allergy Asthma Immunol. Res. 2, 183-187(2010).

9) Losada-Barreiro, S.;Bravo-Díaz, C. Free radicals and polyphenols: The redox chemistry of neurodegenerative diseases. Eur. J. Med. Chem. 133, 379-402 (2017).

10) Lobo, V.; Patil, A.; Phatak, A.; Chandra, N. Free radicals, antioxidants and functional foods: Impact on human health. Pharmacogn. Rev. 4, 118-126 (2010).

11) Enke, C.G.; Nagels, L.J. Undetected components in natural mixtures: How many? What concentrations? Do they account for chemical noise? What is needed to detect them? Anal. Chem. 83, 2539-2546 (2011).

12) Wagner, H.;Ulrich-Merzenich, G. Synergy research: Approaching a new generation of phytopharmaceuticals. Phytomedicine 16, 97-110 (2009).

13) Junio, H.A.; Sy-Cordero, A.A.; Ettefagh, K.A.; Burns, J.T.; Micko, K.T.; Graf, T.N.; Richter, S.J.; Cannon, R.E.; Oberlies, N.H.; Cech, N.B. Synergy-directed fractionation of botanical medicines: A case study with goldenseal (Hydrastis canadensis). J. Nat. Prod. 74, 1621-1629 (2011).

14) Young, I.S.; Trouton, T.G.; Torney, J.J.; McMaster, D.; Callender, M.E.; Trimble, E.R. Antioxidant status and lipid peroxidation in hereditary haemochromatosis. Free Radical Biol. Med. 16, 393-397 (1994).

15) Bhat, S.H.; Azmi, A.S.; Hanif, S.; Hadi, S.M. Ascorbic acid mobilizes endogenous copper in human peripher- 
al lymphocytes leading to oxidative DNA breakage: A putative mechanism for anticancer properties. Int. J. Biochem. Cell Biol. 38, 2074-2081 (2006).

16) Jorge, L.; Reji, N.; Alfredo, P.; Craig, C. Vitamin C-induced oxalate nephropathy. Int. J. Nephrol. 2011, 1-4 (2011).

17) Miller, E.R.,3rd; Pastor-Barriuso, R.; Dalal, D.; Riemersma, R.A.; Appel, L.J.; Guallar, E. Meta-analysis: High-dosage vitamin E supplementation may increase all-cause mortality. Ann. Intern. Med. 142, 37-46 (2005).

18) Touvier, M.; Kesse, E.; Clavel-Chapelon, F.; BoutronRuault, M.-C. Dual association of beta-carotene with risk of tobacco-related cancers in a cohort of French women. J. Natl. Cancer Inst. 97, 1338-1344(2005).

19) Choo, Y.M.; Yap, S.C.; Ooi, C.K.; Ma, A.N.; Goh, S.H. Recovered oil from palm-pressed fiber: A good source of natural carotenoids, vitamin E, and sterols. J. Am. Oil Chem. Soc. 73, 599-602(1996).

20) Lau, H.L.N.; Choo, Y.M.; Chuah, C.H. Quality of residual oil from palm-pressed mesocarp fiber (Elaies guineensis) using supercritical $\mathrm{CO}_{2}$ with and without ethanol. J. Am. Oil Chem. Soc. 83, 893-898(2006).

21) Sulihatimarsyila, A.W.; Lau, H.L.N.; Nabilah, M.; Azreena, I. Refining process for production of refined palmpressed fibre oil. Ind. Crops Prod. 129, 488-494 (2019).

22) Choo, Y.M.; Bong, S.C.; Ma, A.N.; Chuah, C.H. Phospholipids from palm-pressed fiber. J. Am. Oil Chem. Soc. 81, 471-475 (2004).

23) Lau, H.L.N.; Choo, Y.M.; Ma, A.N.; Chuah, C.H. Identification of water-soluble components from palm-pressed fiber. MPOB International Congress, Sunway Pyramid Convention Centre, Selangor, Malaysia, September 2529, 2005, p. 23(2005).

24) Lau, H.L.N.; Choo, Y.M.; Wafti, N.S. A process for refining palm-pressed fibre oil (PPFO) to produce refined oil. Malaysia. WO 2014158011 A1 (2014).

25) Lau, H.L.N.; Nursulihatimarsyila, A.W.; Nur Azreena, I.; Puah, C.W.; Hasliyanti, A.; Nor Fizah, J.; Choo, Y.M. Red palm oil from palm-pressed mesocarp fiber. in Proceedings of the MPOB International Palm Oil Congress (PIPOC 2013), Kuala Lumpur Convention Center (KLCC), Malaysia, pp. 19-21.(2013).

26) Siew, W.L. Palm oil sterols. in Palm Oil Developments, Malaysian Palm Oil Board, Malaysia, pp. 18-19 (1990).

27) Jacobsberg, B. Palm oil characteristics and quality. in Proceedings of the 1st Mardi Workshopon Oil Palm Technology (Chai, O.S.; Awalludin, A. eds.), Malaysian Agriculture Research and Development Institute (MARDI), Kuala Lumpur, pp. 48-68(1974).

28) Gapor, A.M.T.; Hazrina, A.R. Squalene in oils and fats. Palm Oil Dev. 32, 36-40(2000).
29) Eqbal, D.; Halimah, A.S.; Aminah, A.; Halimah, M.; Gapor, A. Vitamin E and beta carotene composition in four different vegetable oils. Am. J. Appl. Sci. 8, 407412(2011).

30) Kumar, P.K.P.; Jeyarani, T.; Krishna, A.G.G. Physicochemical characteristics of phytonutrient retained red palm olein and butter-fat blends and its utilization for formulating chocolate spread. J. Food Sci. Technol. 53, 3060-3072 (2016).

31) Mansouri, F.; Ben moumen, A.; Richard, G.; Fauconnier, M.L.; Sindic, M.; Serghini-Caid, H.; Elamrani, A. Phytosterols composition of virgin olive oils from cultivars introduced in eastern Morocco in comparison to Picholine Marocaine. J. Mater. Environ. Sci. 6, 2322-2329 (2015).

32) Beltran, G.; Bucheli, M.E.; Aguilera, M.P.; Belaj, A.; Jimenez, A. Squalene in virgin olive oil: Screening of variability in olive cultivars. Eur. J. Lipid Sci. Technol. 118, 1250-1253(2016).

33) Cunha, S.C.; Amaral, J.S.; Fernandes, J.O.; Oliveira, M.B. Quantification of tocopherols and tocotrienols in portuguese olive oils using HPLC with three different detection systems. J. Agric. Food Chem. 54, 33513356 (2006).

34) Pollak, O.J. Reduction of blood cholesterol in man. Circulation 7, 702-706 (1953).

35) Shenouda, N.S.; Sakla, M.S.; Newton, L.G.; Besch-Williford, C.; Greenberg, N.M.; MacDonald, R.S.; Lubahn, D.B. Phytosterol Pygeum africanum regulates prostate cancer in vitro and in vivo. Endocrine 31, 72-81 (2007).

36) Awad, A.B.; Chinnam, M.; Fink, C.S.; Bradford, P.G. Beta-sitosterol activates Fas signaling in human breast cancer cells. Phytomedicine 14, 747-754(2007).

37) Choi, Y.H.; Kong, K.R.; Kim, Y.A.; Jung, K.O.; Ki, J.H.; Rhee, S.H.; Park, K.Y. Induction of Bax and activation of caspases during beta-sitosterol-mediated apoptosis in human colon cancer cells. Int. J. Oncol. 23, 16571662 (2003).

38) Awad, A.B.; Hartati, M.S.; Fink, C.S. Phytosterol feeding induces alteration in testosterone metabolism in rat tissues. J. Nutr. Biochem. 9, 712-717(1998).

39) Gabay, O.; Sanchez, C.; Salvat, C.; Chevy, F.; Breton, M.; Nourissat, G.; Wolf, C.; Jacques, C.; Berenbaum, F. Stigmasterol: A phytosterol with potential anti-osteoarthritic properties. Osteoarthr. Cartil. 18, 106-116 (2010).

40) Ciccone, M.M.; Cortese, F.; Gesualdo, M.; Carbonara, S.; Zito, A.; Ricci, G.; De Pascalis, F.; Scicchitano, P.; Riccioni, G. Dietary intake of carotenoids and their antioxidant and anti-inflammatory effects in cardiovascular care. Mediators Inflamm. 2013, 1-11 (2013).

41) Mayne, S.T. Beta-carotene, carotenoids, and disease prevention in humans. FASEB J. 10, 690-701 (1996). 
42) Kelly, G.S. Squalene and its potential clinical uses. Altern. Med. Rev. 4, 29-36(1999).

43) Muller, D.P. Vitamin E and neurological function. Mol. Nutr. Food Res. 54, 710-718(2010).

44) Dowd, P.; Zheng, Z.B. On the mechanism of the anticlotting action of vitamin E quinone. Proc. Natl. Acad. Sci. U.S.A. 92, 8171-8175(1995).

45) Ogbe, R.J.; Ochalefu, D.O.; Mafulul, S.G.; Olaniru, O.B. A review on dietary phytosterols: Their occurrence, metabolism and health benefits. Asian J. Plant Sci. 5, 10-21 (2015).

46) Grimm, M.O.W.; Mett, J.; Hartmann, T. The impact of Vitamin $\mathrm{E}$ and other fat-soluble vitamins on Alzheimer's Disease. Int. J. Mol. Sci. 17, 1785-1802(2016).

47) Kamisah, Y.; Adam, A.; Ngah, W.Z.N.; Gapor, M.T.; Azizah, O.; Marzuki, A. Chronic intake of red palm olein and palm olein produce beneficial effects on plasma lipid profile in rats. Pakistan Journal of Nutrition 4, 89-96 (2005).

48) Kritchevsky, D.; Tepper, S.A.; Kuksis, A.; Wright, S.; Czarnecki, S.K. Cholesterol vehicle in experimental atherosclerosis. 22. Refined, bleached, deodorized (RBD) palm oil, randomized palm oil and red palm oil. Nutr. Res. 20, 887-892 (2000).

49) Esterhuyse, A.J.; du Toit, E.F.; van Rooyen, J. Dietary red palm oil supplementaation protects against the consequences of global ischemia in the isolated perfused rat heart. Asia Pac. J. Clin. Nutr. 14, 340-347 (2005).

50) Marta, G.F.; Frank, B.H.; Miguel, A.M.G.; Montserrat, F.; Monica, B.; Ramon, E.; Emilio, R.; Dolores, C.; Javier, R.; Enrique, G.G.; Miguel, F.; Jose, L.; Lluis, S.M. et al. Olive oil intake and risk of cardiovascular disease and mortality in the PREDIMED Study. BMC Medicine 12, 78-88(2014).

51) Cicerale, S.; Lucas, L.J.; Keast, R.S.J. Antimicrobial, antioxidant and anti-inflammatory phenolic activities in extra virgin olive oil. Current Opin. Biotechnol. 23, 129-135 (2012).

52) Nevin, K.G.;Rajamohan, T. Virgin coconut oil supplemented diet increases the antioxidant status in rats. Food Chem. 99, 260-266 (2006).

53) Lau, H.L.; Puah, C.W.; Choo, Y.M.; Ma, A.N.; Chuah, C.H. Simultaneous quantification of free fatty acids, free sterols, squalene, and acylglycerol molecular species in palm oil by high-temperature gas chromatography--flame ionization detection. Lipids 40, 523-528 (2005).

54) MPOB Test Method p2.6 Determination of carotene content (2004).

55) Che, H.L.; Tan, D.M.Y.; Meganathan, P.; Gan, Y.L.; Razak, G.A.; Fu, J.Y. Validation of a HPLC/FLD Method for quantification of tocotrienols in human plasma. Int. J. Anal. Chem. 2015, 1-7(2015).
56) Radhia, F.; Lekbir, A.; Ouadah, H.; Kahoul, M.A.; Khlalfa, L.; Laroui, S.; Alloui-Lombarkia, O. Effect of extraction solvent on total phenolic content, total flavonoid content, and antioxidant activities of Algerian pomace olive oil. Int. Food Res. J. 24, 2295-2303 (2017).

57) Abdullah, F.; Ismail, R.; Ghazali, R.; Idris, Z. Total phenolic contents and antioxidant activity of palm oils and palm kernel oils at various refining processes. J. Oil Palm Res. 30, 682-692(2018).

58) Teh, S.S.; Ee, G.C.L.; Mah, S.H.; Yong, Y.K.; Lim, Y.M.; Rahmani, M.; Ahmad, Z. In vitro cytotoxic, antioxidant, and antimicrobial activities of Mesua beccariana (Baill.) Kosterm., Mesua ferrea Linn., and Mesua congestiflora extracts. BioMed Res. Int. 2013, 9 (2013).

59) Fernando, C.D.; Soysa, P. Optimized enzymatic colorimetric assay for determination of hydrogen peroxide $\left(\mathrm{H}_{2} \mathrm{O}_{2}\right)$ scavenging activity of plant extracts. MethodsX 2, 283-291 (2015).

60) Parul, R.; Kundu, S.K.; Pijush, S. In vitro nitric oxide scavenging activity of methanol extracts of three Bangladeshi medicinal plants. The Pharma Innovation Journal 1, 83-88(2012).

61) Mah, S.H.; Teh, S.S.; Ee, G.C.L. Anti-inflammatory, anti-cholinergic and cytotoxic effects of Sida rhombifolia. Pharm. Biol. 55, 920-928(2017).

62) Visioli, F.; Poli, A.; Gall, C. Antioxidant and other biological activities of phenols from olives and olive oil. Med. Res. Rev. 22, 65-75(2002).

63) Tripoli, E.; Giammanco, M.; Tabacchi, G.; Di Majo, D.; Giammanco, S.; La Guardia, M. The phenolic compounds of olive oil: Structure, biological activity and beneficial effects on human health. Nutr. Res. Rev. 18, 98-112(2005).

64) Varvara, M.; Bozzo, G.; Celano, G.; Disanto, C.; Pagliarone, C.N.; Celano, G.V. The use of ascorbic acid as a food additive: technical-legal issues. Italian Journal of Food Safety 5, 4313-4313 (2016).

65) Loganathan, R.; Radhakrishnan, A.K.; Selvaduray, K.R.; Nesaretnam, K. Selective anti-cancer effects of palm phytonutrients on human breast cancer cells. $R S C$ Adv. 5, 1745-1753 (2015).

66) Balasundram, N.; Ai, T.; Sambanthamurthi, R.; Sundram, K.; Samman, S. Antioxidant properties of palm fruit extracts. Asia Pac. J. Clin. Nutr 14, 319-324 (2005).

67) Power, M.L.; Koutsos, L. Chapter 4 - Marmoset Nutrition and Dietary Husbandry. in The Common Marmoset in Captivity and Biomedical Research (Marini, R.; Wachtman, L.; Tardif, S.; Mansfield, K.; Fox, J. eds.), Academic Press, pp. 63-76 (2019).

68) Yoshida, Y.; Niki, E. Antioxidant effects of phytosterol and its components. J. Nutr. Sci. Vitaminol. 49, 4, 277-280 (2003). 
69) Traber, M.G.;Atkinson, J. Vitamin E, antioxidant and nothing more. Free Radical Biol. Med. 43, 4-15 (2007).

70) McArthur, J.A.; Bambach, B.; Duncan, C.; Talano, J.-A.; Tamburro, R.T. Pediatric Critical Care, 4th ed. Mosby, Saint Louis, pp. 1177-1190 (2011).

71) Mohan, C.; Balamurugan, V.; Salini, S.; Rekha, R. Metal ion chelating activity and hydrogen peroxide scavenging activity of medicinal plant Kalanchoe pinnata. J. Chem. Pharm. Res. 4, 197-202(2012).

72) García-Casal, M.N.; Leets, I. Carotenoids, but not vitamin A, improve iron uptake and ferritin synthesis by Caco-2 cells from ferrous fumarate and NaFe-EDTA. $J$.
Food Sci. 79 (4), H706-712(2014).

73) Rohman, A.; Riyanta, A.B.; Lukitaningsih, E.; Riyanto, S. Olive (Olea europea) oil: Physico-chemical characterization and antioxidant activities in vitro and in vivo. Food Res. 4, 563-570(2019).

CC BY 4.0 (Attribution 4.0 International). This license allows users to share and adapt an article, even commercially, as long as appropriate credit is given. That is, this license lets others copy, distribute, remix, and build upon the Article, even commercially, provided the original source and Authors are credited. 